\title{
Izhodišča pri izboru in načinu umeščanja vrtnic (Rosa spp.) na javne in poljavne mestne površine: primer četrtne skupnosti Bežigrad, Lju- bljana
}

\author{
Nina KUNC ${ }^{1,2}$, Valentina SCHMITZER ${ }^{1}$
}

Received May 06, 2020; accepted September 07, 2021. Delo je prispelo 6. Maja 2020, sprejeto 7. septembra 2021

Preferences in selection and planting types of roses (Rosa spp.) in urban public and semi-public areas: a case study of Bežigrad community, Ljubljana

Abstract: Roses have an indisputable leading role in private gardens. They also appear in public areas. They are very interesting plants for public urban areas because they represent aesthetic, ecological, tehnical and sociological potential. In public areas varietes are selected according to various criteria such as resistance to heat, low temperatures an drought, repetitive flowering and ease of maintenance. The aim of our study is to present preferences in the selection of groups of roses, their colors, types of plantings, the abudance of roses in planting and the height of individual roses on difrent subtypes of public ans semi-public green areas of the Bežigrad community, Ljubljana. The results of the study showed that the most comomn roses in urban public areas are floribundas. Dominated type of planting is a few plants together in a group. In neighborhoods and block settlements are dominated individual plants. The most common color of roses is red. In urban public areas are planted only roses up to $1 \mathrm{~m}$ height. In semi-public areas are also higher roses. The abudance of roses in semi-urban areas varies from 1 to over 30 roses in planting. In urban public areas are most common planting with 10 to 20 roses and those with more than 30 roses.

Key words: roses; urban public areas; urban semi-public areas; community of Bežigrad
Izhodišča pri izboru in načinu umeščanja vrtnic (Rosa spp.) na javne in poljavne mestne površine: primer četrtne skupnosti Bežigrad, Ljubljana

Izvleček: Vrtnice so na slovenskih zasebnih vrtovih zelo pogoste okrasne rastline, vedno bolj pa se sadijo tudi na javne površine. So zelo zanimive rastline za javne mestne površine, saj predstavljajo estetski, ekološki, tehnični in sociološki potencial. Za javni mestni prostor se izbira sorte po kriterijih, kot so: odpornost na vročino, nizke temperature, sušo, ponavljajoče cvetenje in enostavnost vzdrževanja. Namen naše raziskave je bil predstaviti preference pri izboru skupin vrtnic, njihove barve, vrste zasaditev, številčnost vrtnic $\mathrm{v}$ zasaditvi ter višina posameznih vrtnic na različnih podtipih javnih in poljavnih zelenih površinah četrtne skupnosti Bežigrad, Ljubljana. Rezultati raziskave so pokazali, da so na javni površini najpogostejše mnogocvetne vrtnice. Prevladujejo zasaditve po nekaj rastlin skupaj v gruči, medtem ko v soseskah in blokovskih naseljih prevladujejo posamezne rastline. Najpogostejša barva vrtnic je rdeča. $\mathrm{Na}$ javnih mestnih površinah so zasajene samo vrtnice, ki dosežejo višino $1 \mathrm{~m}$, na poljavnih pa tudi višje. Številčnost vrtnic na poljavnih mestnih površinah je različna, vse od 1 do nad 30 vrtnic v zasaditvi. Na javnih mestnih površinah smo opazili predvsem zasaditve z 10 do 20 vrtnicami in pa take, kjer je bilo vrtnic nad 30 .

Ključne besede: vrtnice; javne mestne površine; poljavne mestne površine; četrtna skupnost Bežigrad

1 Univerza v Ljubljani, Biotehniška fakulteta, Oddelek za agronomijo, Jamnikarjeva 101, 1000 Ljubljana, Slovenija

2 Korespondenčni avtor, e-naslov: ninakunc123@gmail.com 


\section{UVOD}

Vrtnice so na slovenskih zasebnih vrtovih zelo pogoste okrasne rastline, vedno bolj pa se sadijo tudi na javne mestne površine, saj nekatere uspevajo v razmeroma neugodnih razmerah in jih odlikuje dolgo obdobje cvetenja. $\mathrm{V}$ javnem mestnem prostoru sorte vrtnic izbiramo po kriterijih, kot so odpornost na vročino, nizke temperature in sušo, ponavljajoče cvetenje, enostavnost vzdrževanja ter odpornost proti rastlinskim boleznim. Zaradi izjemne raznolikosti in sortne pestrosti vrtnice delimo v skupine, ki se razlikujejo po načinu rasti, morfologiji, zahtevnosti vzdrževanja in namenu sajenja. V javne mestne nasade se večinoma sadi manj zahtevne skupine vrtnic, ki jih v prostor najpogosteje umeščajo $\mathrm{v}$ obliki živih mej, obrob ali kot talne prekrovne rastline. Plezalke in vzpenjalke so $\mathrm{v}$ javnem mestnem prostoru manj zastopane, saj je njihovo vzdrževanje zahtevnejše (Zgonec, 1981; Cottini, 2003).

Ker se površine namenjene zelenju $v$ mestih krčijo in so velikokrat umeščene zgolj v obcestni prostor, je smotrno izbrati rastline, ki zavzemajo večplastno vlogo. Vrtnice so na javnih površinah zato izjemno zanimive rastline, saj v stanovanjske soseske in širši mestni prostor vnašajo barvitost (estetski potencial), predstavljajo pašo za čebele in mesta za gnezdenje ptic (ekološki potencial), so primerne za sajenje na nagnjene površine zmernih nagibov (tehnični potencial) in priljubljene pri večini prebivalcev (sociološki potencial).

V raziskavi želimo predstaviti preference pri izboru skupin vrtnic (rožni grmi, pritlikave vrtnice, plezalke, prekrovne vrtnice, mnogocvetne, debelne vrtnice, retrovrtnice, vzpenjalke, poliante, atrijske, velecvetne vrtnice...), njihove barve, vrste nasadov, številčnost vrtnic $\mathrm{v}$ nasadu ter višina posameznih vrtnic na različnih podtipih javnih (javni parki, nasadi, drevoredi, zelenice, zelene površine ob javnih cestah lokalnih poteh in drugih javnih komunikacijah ter vodnih površinah, zelene površine ob spomeniških, zgodovinskih ter posameznih turističnih objektih $\mathrm{v}$ javni lasti ali če je njihovo urejanje v pristojnosti občine in zelene površine na pokopališčih) in poljavnih mestnih zelenih površinah (zelene površine pred gostinskimi objekti, lokali, televizijskimi objekti, pošto, sosesko, blokovskim naseljem, izobraževalnimi ustanovami in zdravstvenimi ustanovami) in poljavnih mestnih površin, na primeru četrtne skupnosti Bežigrad, Ljubljana. Uporabili smo izsledke na podlagi magistrskega dela (Kunc, 2019). Dobljene podatke raziskave želimo primerjati s preferencami izbora vrtnic glede na barvo, višino ter druge parametre, $v$ državah po svetu.

\section{MATERIALI IN METODE}

Četrtna skupnost Bežigrad je ena izmed 17 četrtnih skupnosti v Ljubljani in po številu prebivalcev druga največja četrtna skupnost (Mestna občina Ljubljana, 2019). Na dan 31. 12. 2018 jih je imela 35.200. Zajema 724 ha površine in vključuje ljubljanske severne četrti: Bežigrad, Zupančičeva jama, Savsko naselje, Rapova jama, del Jarš, Tomačevo, BS 3, Študentsko naselje, Brinje in Stadion. Meje četrtne skupnosti so: na jugu Kurilniška ulica, Vilharjeva c. do Savske c. Na vzhodu Savska c., Žalska c. - mimo pokopališča, preko Groblja in Save. Na severu do levega brega Save in nato do krožišča Tomačevo. Območje zajema tudi del Jarš in Tomačevega. Proti zahodu poteka meja po obvoznici do podvoza pod kamniško progo. Na zahodu pa vzdolž kamniške proge mimo gorenjske železniške postaje do Kurilniške ulice, kjer se pentlja zaključi (Četrtna skupnost Bežigrad, 2019; Četrtna skupnost Bežigrad, 2015).

Kot glavno metodo našega raziskovalnega dela smo uporabili terensko raziskavo analiziranega območja. Analizo smo opravili v času polnega cvetenja, junija leta 2019. S pomočjo karte četrtne skupnosti Bežigrad smo ugotovili točne lokacije pojavljanja vrtnic. Poleg tega smo pridobili tudi informacije o tem, katere od analiziranih mestnih površin so javne ter katere so poljavne. Območje četrtne skupnosti Bežigrad smo sistematično terensko pregledovali. Zabeležili smo si lokacijo, skupino vrtnic, njihovo barvo, vrsto zasaditve, številčnost vrtnic $\mathrm{v}$ zasaditvi, višino rastlin ter podtip javne oziroma poljavne površine na kateri se vrtnice nahajajo. Stanje na terenu smo fotografirali.

$\mathrm{Na}$ koncu smo vse dobljene podatke statistično obdelali in rezultate grafično prikazali ter rezultate primerjali $z$ rezultati raziskav o vrtnicah na javnih mestnih površinah $\mathrm{v}$ drugih državah.

\section{$3 \quad$ REZULTATI IN DISKUSIJA}

Vrtnice se na javnih površinah nahajajo na Vojkovi cesti ob stavbi Upravne enote Ljubljana, izpostava Bežigrad ter pred pietetnim objektom (Žale) in v javnem parku (Park literatov). Na poljavnih površinah smo jih opazili pred gostinskima objektoma gostilna Pod kostanji in Vivo catering. Pred televizijskim objektom (POP TV), pred Pošto na Dunajski cesti. Največje število jih je bilo v soseskah in blokovskih naseljih. Lokacije, kjer smo jih opazili so: Peričeva, Ptujska, Linhartova ulica, Ulica Metoda Mikuža, Študentski dom na Vojkovi ulici, Črtomirova, Neubergerjeva, Topniška, Smoletova ulica, Ulica Pohorskega bataljona, Šarhova, Hubadova, Pegamova, Glavarjeva, Mašera-Spasića, BS3 balinarsko 
društvo, Turnerjeva ulica, Ulica Luize Pesjakove, Majaronova in Šerkova ulica. Poleg tega smo jih opazili še pri izobraževalnih ustanovah: Univerza v Ljubljani Fakulteta za socialno delo (Topniška ulica), Vrtec Mladi rod: Enota Mavrica (Črtomirova ulica), Vrtec Jekla (Glavarjeva ulica), Osnovna šola Bežigrad (Črtomirova ulica), Osnovna šola Franceta Bevka (Ulica Pohorskega bataljona), Univerzitetni rehabilitacijski Inštitut Republike Slovenije - Soča (Linhartova ulica). Manjši nasad smo opazili tudi pred Poslovno hišo Slovenčeva (PHS), na Slovenčevi ulici (Karta četrtne skupnosti..., 2019).

\subsection{PRISOTNOST SKUPIN}

$\mathrm{Na}$ analiziranem območju smo opazili 1466 vrtnic. Od tega se jih je $873(57,1 \%)$ nahajalo na javnih ter $629(42,9 \%)$ na poljavnih mestnih površinah. Skupine vrtnic na posameznih tipih površin so prikazane v pre-

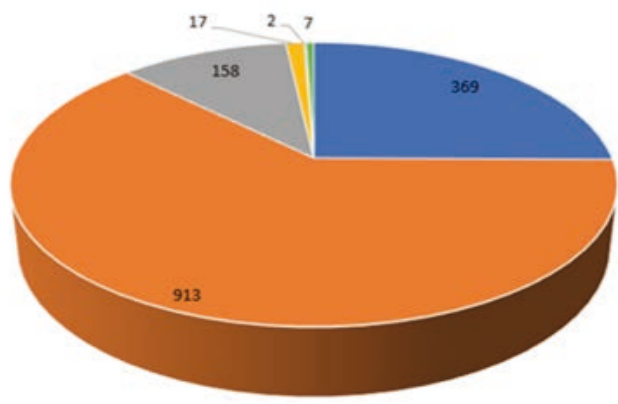

- rožni grmi "mnogocvetne " prekrovne "portland " plezalke " debelne

Slika 1: Analiza prisotnih skupin vrtnic na javnih in poljavnih mestnih površinah četrtne skupnosti Bežigrad

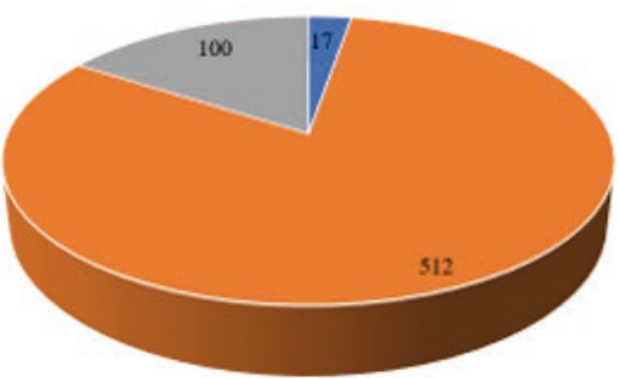

- rožni grmi "mogocvetne "prekrovne glednici 1. Prevladujejo mnogocvetne vrtnice. Teh je na analiziranem območju $62,3 \%$. Sledijo rožni grmi, ki jih je $25,2 \%$. Prekrovnih vrtnic je $10,8 \%$, vrtnic,Portland je $1,1 \%, 0,5 \%$ je debelnih in $0,2 \%$ je plezalk (Slika 1 ).

$\mathrm{Na}$ javnih mestnih površinah so močno prevladovale mnogocvetne vrtnice $(81,4 \%)$, v manjšem deležu so se pojavljale še prekrovne vrtnice $(15,9 \%)$ in rožni grmi $(2,7 \%)$ (Slika 2). Raznolikost skupin na poljavnih mestnih površinah je bolj pestra. $V$ največjem deležu so zastopane mnogocvetne vrtnice (48 \%), takoj za njimi sledijo rožni grmi $(42,1 \%)$. V manjših deležih pa smo opazili še prekrovne vrtnice $(6,9 \%)$, vrtnice portland (2 $\%)$, debelne vrtnice $(0,8 \%)$ in plezalki $(0,2 \%)$ (Slika 2$)$.

Mnogocvetne vrtnice imenujemo tudi floribunde, klobčasto ali šopastocvetne vrtnice. Zaradi dobrega zdravstvenega stanja in odpornosti proti boleznim in škodljivcem so zelo primerne za sajenje na javne površine. Med prvim cvetenjem zrastejo do $70 \mathrm{~cm}$ visoko. Rožni grmi so višji od mnogocvetnih vrtnic in prav tako zelo primerni za sajenje na javnih površinah. Njihova povprečna končna višina znaša okrog $200 \mathrm{~cm}$. Prekrovne vrtnice temeljito prerastejo tla. Lahko so polegle čisto po tleh, lahko so višine mnogocvetnih vrtnic, ali pa dosežejo višino rožnih grmov. Na javnih površinah nadomeščajo mnogocvetne vrtnice. Vrtnice ,Portland' imajo pokončno rast in na javnih površinah niso pogoste. Plezalke zrastejo od 3 do $8 \mathrm{~m}$ visoko. Primerne so za plezanje po lokih, ograjah, senčnicah in stebrih. So zahtevne za gojenje, zato se na javnih površinah ne pojavljajo pogosto. Debelne vrtnice so pokončne ali povešave rasti $\mathrm{z}$ deblom visokim $75 \mathrm{do} 150 \mathrm{~cm}$ in imajo obliko drevesa. Zaradi težavnega vzdrževanja se $\mathrm{v}$ javnem prostoru ne pojavljajo pogosto (Sojer, 2019; Cotini, 2003; Mastnak, 2008; Zgonec, 1981; Wilson Nurseries..., 2019; Garden Grower, 2010).

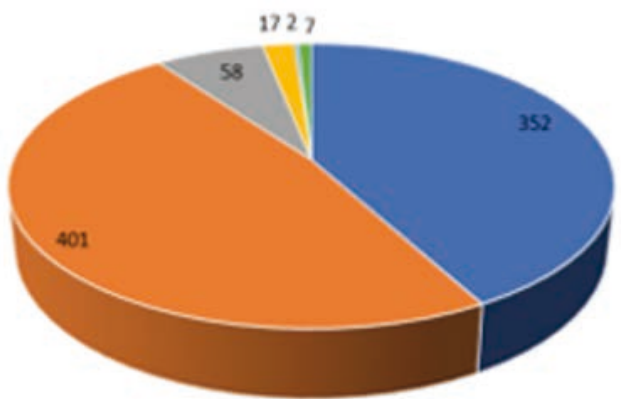

- rotni grmi $=$ mnogocvetne $*$ prekrovne $*$ portland $*$ plezalke $*$ debelne

Slika 2: Analiza prisotnih skupin vrtnic na javnih (levo) in poljavnih (desno) mestnih površinah v četrtni skupnosti Bežigrad 
Preglednica 1: Skupine vrtnic na posameznih tipih mestnih površin v četrtni skupnosti Bežigrad

\begin{tabular}{|c|c|}
\hline Skupine vrtnic & Tipi površin \\
\hline Mnogocvetne & $\begin{array}{l}\text { Javne površine (pietetni objekt, park), poljavne površine (gostinski objekt, soseske in blokovska naselja, } \\
\text { izobraževalne ustanove, poslovna stavba) }\end{array}$ \\
\hline Rožni grmi & Javne površine (pietetni objekt), poljavne površine (gostinski objekt, Pošta, soseske in blokovska naselja) \\
\hline Prekrovne & $\begin{array}{l}\text { Javne površine (občinski objekt), poljavne površine (gostinski objekt, televizijski objekt, Pošta, soseske in } \\
\text { blokovska naselja, izobraževalne ustanove) }\end{array}$ \\
\hline Portland & Poljavne površine (soseske in blokovska naselja) \\
\hline Plezalke & Poljavne površine (soseske in blokovska naselja) \\
\hline Debelne & Poljavne površine (izobraževalne ustanove) \\
\hline
\end{tabular}

\subsection{VRSTE NASADOV}

Vrtnice se na analiziranem območju pojavljajo v treh tipih nasadov: kot posamezne rastline, po nekaj skupaj v gruči in kot linijski nasad. Na celotnem območju prevladujejo lokacije, kjer rastejo posamezne rastline (46,5\%), malo manj je nasadov v gruči $(30,2 \%)$, najmanj pa je linijskih nasadov (10 \%) (Sliki 3 in 4).

$\mathrm{Na}$ javnih mestnih površinah prevladujejo vrtnice, ki so posajene po nekaj skupaj v gruči (50 \%) (slika 6), sledijo linijski nasadi $(31,25 \%)$, najmanj je posameznih rastlin (18,75\%) (slika 5).

$\mathrm{V}$ primerjavi z vrstami nasadov na lokacijah na javnih mestnih površinah je precej drugačno stanje $\mathrm{v}$ soseskah in blokovskih naseljih. S kar $63 \%$ prevladujejo lokacije, kjer so vrtnice posajene posamezno, v kombinaciji z drugimi okrasnimi rastlinami (Slika 7). V enakih deležih $(18,5 \%)$ se pojavljajo $\mathrm{v}$ linijskih nasadih in $\mathrm{v}$ nasadih v gruči (Slika 8).

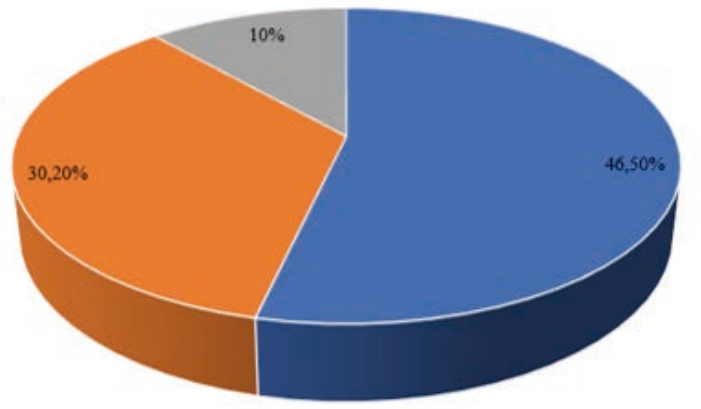

" posamezne "po nekaj skupaj v gruči = linijska zasaditev

Slika 3: Analiza vrste nasadov na javnih in poljavnih mestnih površinah četrtne skupnosti Bežigrad

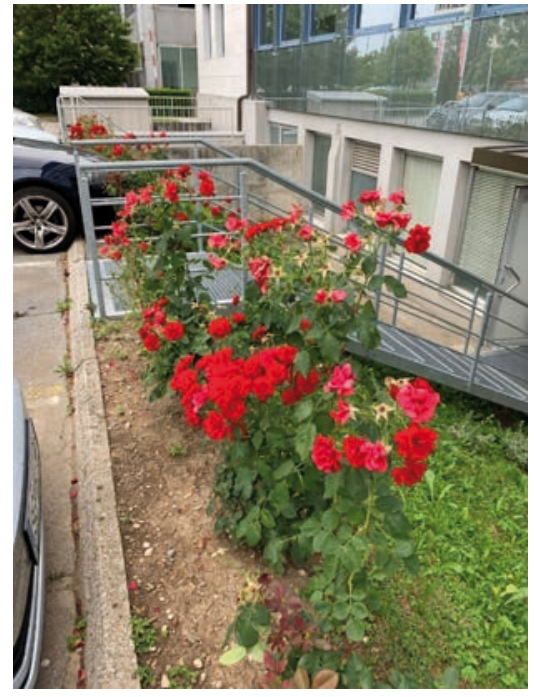

Slika 4: Primer linijskega nasada pred vhodom v Poslovno hišo Slovenčeva

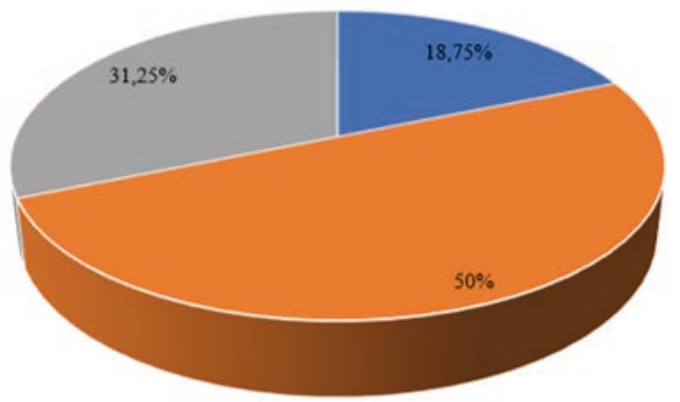

- posamezne "po nekaj skupaj v gruči = linijska zasaditev

Slika 5: Analiza vrste nasadov na javnih mestnih površinah v četrtni skupnosti Bežigrad 


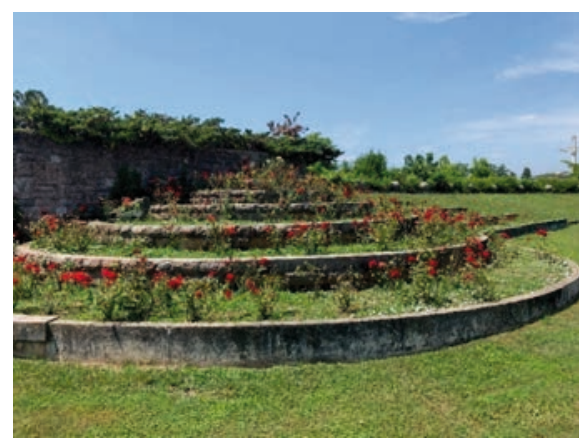

Slika 6: Primer nasadov po nekaj rastlin skupaj v gruči na območju Žal

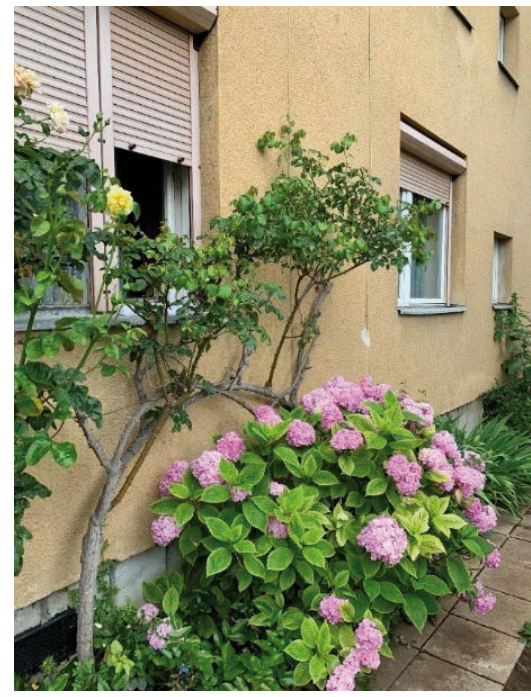

Slika 7: Primer posameznega nasada na območju sosesk in blokovskih naseljih v četrtni skupnosti Bežigrad

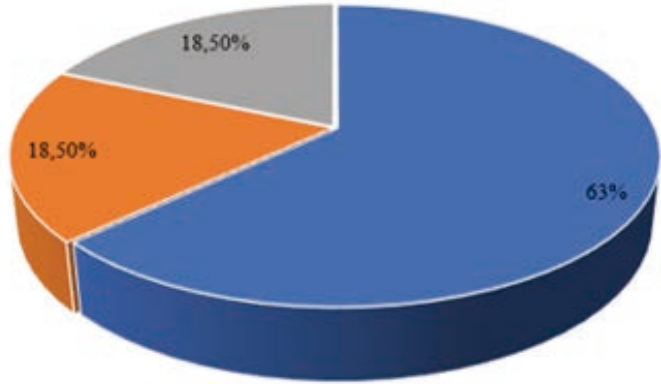

= posamezne "po nekaj skupaj v gruci " linijska zasaditev

Slika 8: Analiza vrste nasada v soseskah in blokovskih naseljih v četrtni skupnosti Bežigrad

\subsection{BARVA}

Nasadi vrtnic so barvno usklajeni. Večji nasadi so roza, rdeče, oranžne ali pa bele barve.

$\mathrm{Na}$ celotnem analiziranem območju prevladujejo rdeče vrtnice, teh je 49,3\%, sledijo roza, ki jih je $31,4 \%$, belih je $8,8 \%$, oranžnih je $6,1 \%$, vijolično-rdečih je 2,4 $\%$, roza-oranžnih je $1,5 \%$ in $0,5 \%$ je rumenih (Slika 9 ).

Na poljavnih površinah prevladujejo rdeče vrtnice, ki jih je 42,8\%, sledijo jim roza, ki jih je 41,7 \%, 7,8 \% je belih, $4,4 \%$ je oranžnih , $2,4 \%$ je roza-oranžnih in 0,9 $\%$ je rumenih (Slika 10). Podobna barvna sestava je tudi na javnih površinah. Prevladujejo rdeče (58 \%), sledijo roza $(17,6 \%)$, belih je $(10,2 \%)$, oranžnih $(8,5 \%)$. Se pa na javnih površinah pojavljajo tudi vijolično-rdeče vrtnice. Teh je najmanj in sicer 5,7 \% (Slika 11).

\subsection{VIŠINA VRTNIC}

Po višini smo vrtnice razdelili $\mathrm{v} 4$ velikostne razrede: $0-1 \mathrm{~m}, 1-2 \mathrm{~m}, 2-3 \mathrm{~m}$ in $3 \mathrm{~m}$ in več (Preglednica 2). Opaziti je možno, da se na javne mestne površine sadi samo vrtnice, ki zrastejo do $1 \mathrm{~m}$. Medtem, ko se za poljavne površine izbira vrtnice vseh štirih velikostnih skupin.

\section{5 ŠTEVILČNOST VRTNIC V NASADU}

Glede na številčnost vrtnic v nasadu smo jih razdelili v 4 različne skupine: $0-10,10-20,20-30$ in nad 30. Podatki so zbrani v Preglednici 3, iz katere je mogoče razbrati, da se $\mathrm{v}$ vseh 4 skupinah pojavljajo vrtnice na poljavnih površinah. Na javnih površinah pa se pojavljajo samo v skupini $10-20$ in nad 30 .

Za primerjavo smo pregledali preference pri izboru vrtnic za javne mestne površine drugod po svetu. Na sarajevskih (Avdić in sod., 2013) javnih mestnih površinah so prevladovale velecvetne vrtnice $(48,94 \%)$. Takoj za njimi so bile mnogocvetne vrtnice $(46,81 \%)$, $\mathrm{v}$ enakem majhnem deležu pa so se pojavljale še vzpenjalke in samonikli šipki. Glede barve, za razliko od bežigrajskih barvno usklajenih nasadov, sadijo skupaj popolnoma naključne barve. Na splošno pa v Sarajevu prevladujejo vrtnice bele in roza barve.

V Pekingu (Wang in sod., 2017) je najpogostejša rdeča barva vrtnic (57\%).V manjšem deležu se udi rumene, bele in večbarvne vrtnice. $\mathrm{V}$ Pekingu so nasadi precej večji kot na našem analiziranem območju. $40 \%$ nasadov je z manj kot 100 vrtnicami, $24 \%$ pa takih, kjer raste med 100 in 200 vrtnic. Tudi tukaj za javne površi ne izbirajo sorte, katerih višina ne presega $1 \mathrm{~m}$. 
Iranska raziskava preferenc (Rahnema in sod., 2018) okrasnih rastlin med obiskovalci njihovih mestnih parkov je pokazala, da so vrtnice s $25 \%$, takoj za tulipani, druge najbolj priljubljene okrasne rastline. Tudi prebivalci Irana imajo najraje rdečo barvo $(52,1$ \%) cvetov, sledi vijolična in oranžna.

Vrtnice so priljubljene okrasne rastline na poljavnih in zasebnih površinah tudi v Turčiji (Gurkan Kaya in sod., 2018). V Antalyji so vrtnice zasedle četrto mesto med rastlinami, ki se najpogosteje pojavljajo na poljavnih iz zasebnih površinah. Pred njimi so le limonovci, pinije in pomarančevci.

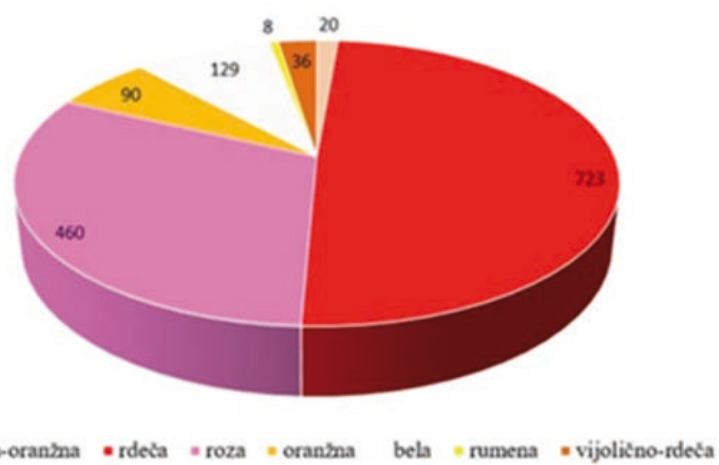

Slika 9: Analiza barve cvetov vrtnic na javnih in poljavnih površinah četrtne skupnosti Bežigrad

Preglednica 2: Višina vrtnic na različnih tipih mestnih površin v četrtni skupnosti Bežigrad

\begin{tabular}{|c|c|}
\hline Višina vrtnic & Tipi površin \\
\hline $0-1 \mathrm{~m}$ & $\begin{array}{l}\text { Javne površine (občinski objekt, pietetni objekt, park) in poljavne površine (gostinski objekt, soseske in blokov- } \\
\text { ska naselja, izobraževalne ustanove, televizijski objekt, Pošta) }\end{array}$ \\
\hline $1-2 m$ & Poljavne površine (izobraževalne ustanove) \\
\hline $2-3 \mathrm{~m}$ & Poljavne površine (pietetni objekt, Pošta, gostinski objekt, soseske in blokovska naselja) \\
\hline $3 \mathrm{~m}$ in več & Poljavne površine (soseske in blokovska naselja) \\
\hline
\end{tabular}

Preglednica 3: Številčnost vrtnic v nasadu na različnih tipih mestnih površin v četrtni skupnosti Bežigrad

\begin{tabular}{ll}
\hline Številčnost vrtnic v nasadu & Tipi površin \\
\hline $0-10$ & $\begin{array}{l}\text { Poljavne površine (gostinska objekta, televizijski objekt, Pošta, soseske in blokovska naselja, } \\
\text { izobraževalne ustanove) }\end{array}$ \\
$10-20$ & $\begin{array}{l}\text { Javne površine (pietetni objekt), poljavne površine (soseske in blokovska naselja, poslovna } \\
\text { stavba) }\end{array}$ \\
Poljavne površine (soseske in blokovska naselja, izobraževalne ustanove) \\
Nad 30 30 & $\begin{array}{l}\text { Javne površine (občinski objekt, pietetni objekt, park) in poljavne površine (soseske in blokov- } \\
\text { ska naselja) }\end{array}$ \\
\hline
\end{tabular}

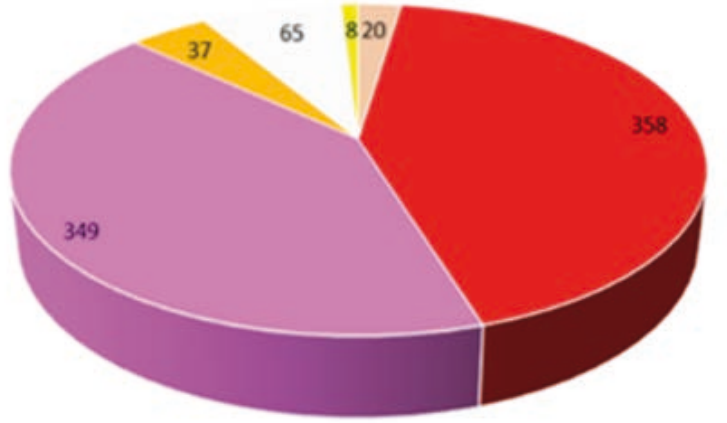

" roza-oranžna = rdeça = roza " oranžna bela "rumena

Slika 10: Analiza barve cvetov na poljavnih mestnih površinah četrtne skupnosti Bežigrad

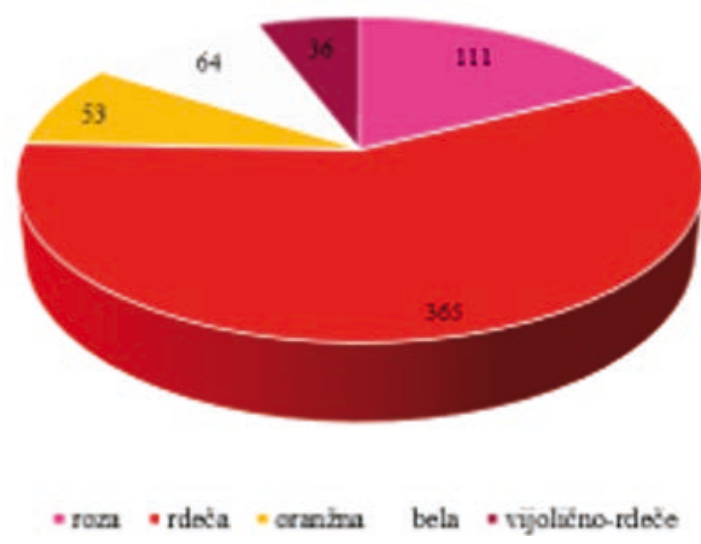

Slika 11: Analiza barve cvetov vrtnic na javnih mestnih površinah četrtne skupnosti Bežigrad 


\section{SKLEPI}

Iz ugotovitev lahko zaključimo, da so tako na javnih kot tudi na poljavnih površinah najbolj zastopane mnogocvetne vrtnice. $\mathrm{Na}$ analiziranem območju smo opazili 1466 vrtnic, od tega se jih je 57,1\% nahajalo na javnih, ter $42,9 \%$ na poljavnih površinah. Prevladujejo mnogocvetne vrnice, sledijo rožni grmi, prekrovne vrtnice in vrtnice portland. Najmanj pa je debelnih vrnic in plezavk. Vzrok za tako redko pojavnost omenjenih skupin je v tem, da so težje za gojenje ter vzdrževanje. $\mathrm{Na}$ javnih površinah so najpogostejši nasadi po nekaj vrtnic skupaj v gruči, medtem ko v soseskah in blokovskih naseljih močno prevladujejo posamezne rastline. Barvna sestava vrtnic ni pestra. Močno prevladuje rdeča, v manjših deležih pa se pojavljajo tudi roza, oranžne, bele, rumene, roza-oranžne in vijolično-rdeče. Za poljavne površine se izbira vrtnice vseh velikostnih skupin, medtem ko za javne površine samo vrtnice višine do $1 \mathrm{~m}$. Glede številčnosti rastlin v nasadu lahko sklepamo, da se v vseh 4 skupinah pojavljajo vrtnice na poljavnih površinah. Na javnih površinah pa se pojavljajo samo v skupini $10-20$ in nad 30. Ugotovili smo, da se vrtnice $\mathrm{v}$ soseskah in blokovskih naseljih pojavljajo $\mathrm{v}$ kombinaciji z drugimi okrasnimi rastlinami. Za razliko od omenjenih območij pa se na ostalih analiziranih lokacijah vrtnice pojavljajo kot samostojne rastline oziroma $\mathrm{v}$ nasadih vrtnic.

\section{VIRI}

Avdić J., Bečić B., Sarajlič N., Arar K. (2013). Roses (Rosa spp.) in public green spaces of Sarajevo. Works of the Faculty of agriculture and food sciences, University of Sarajevo, 61, 66/1: 209-212

Cottini P. (2003). Vrtnice, sorte in način gojenja (izbira, sajenje, nega, obrezovanje). Ljubljana, Rože in vrt, Delo Revije: 34 str.
Četrtna skupnost Bežigrad. (2015). Wikipedija. https:// sl.wikipedia.org/wiki/Četrtna_skupnost_Bežigrad

Četrtna skupnost Bežigrad. Mestna občina Ljubljana. (2019). https://www.ljubljana.si/sl/moja-ljubljana/cetrtne-skupnosti-v-ljubljani/cetrtne-skupnosti-v-ljubljani-2/cetrtna-skupnost-bezigrad/

Gurkan Kaya L., Kaynakci-Elinc Z., Yucedag C., Cetin M. (2018). Enviromental outdoor plant preferences: A practical approach for choosing outdoor plants in urban or suburban residental areas in Antalya, Turkey. Fresenius Enviromental Bulletin, 27(12), 7945-7952

Garden Grower. (2010). http://www.garden-grower.com/ flowers/pruning-roses.shtml (21.2. 2019)

Rahnema S., Sedaghathoor S., Sadegh Allahyari M., Damalas C. A., El Bailali H. (2018). Preferences and emotion perceptions of ornamental plant species for green space designing among urban park users in Iran. Urban Forestry \& Urban Greening, 30, 1-11.

Karta četrtne skupnosti Bežigrad, (2019). Naš Bežigrad. Glasilo četrtne skupnosti Bežigrad Mestne občine Ljubljana, 8(1), 12-13.

Kunc N. (2019). Izbor in pojavnost vrtnic (Rosa spp. ) na javnih površinah v Mestni občini Ljubljana, četrtna skupnost Bežigrad. Magistrsko delo. Ljubljana, Univerza v Ljubljani, Biotehniška fakulteta, Oddelek za agronomijo: 44 str.

Mastnak M. (2008). Vrtnice. Ljubljana, Kmečki glas: 184 str.

Mestna občina Ljubljana. (2019a).Wikipedija. https://sl.wikipedia.org/wiki/Mestna_občina_Ljubljana

Sojer E. (2019). Rast in razvoj vrtnic (Rosa spp.) v prvem letu po presajanju. Diplomsko delo (VS). Ljubljana, Univerza v Ljubljani, Biotehniška fakulteta, Oddelek za agronomijo: 35 str.

Wang H., Yang Y., Li M., Liu J.,, Jin W. (2017). Residents‘ preferences for roses. Features of rose plantings and the relations between them in built-up areas of Beijing, China. Urban Foestry \& Urban Greening, 27, 1-8. https://doi. org/10.1016/j.ufug.2017.06.011

Wilson Nurseries \& Landscape Supply. (2019). Basic Rose Care: 2 str. https://www.wilsonnurseries.com/wp-content/ uploads/2015/01/Basic-Rose-Care.pdf (2.3. 2019)

Zgonec S. (1981). Vrtnice. Ljubljana, ČZP Kmečki glas: 191 str 